\title{
Integrated Scenario Planning and Multi-Criteria Decision Analysis Framework with Application to Forest Planning
}

\author{
Livia Bizikova1, Emina Krcmar² \\ ${ }^{1}$ International Institute for Sustainable Development (IISD), Ottawa, Canada \\ ${ }^{2}$ Faculty of Forestry, University of British Columbia, Vancouver, Canada \\ Email: Ibizikova@iisd.ca, ekrcmar@mail.ubc.ca
}

Received 2 January 2015; accepted 22 January 2015; published 26 January 2015

Copyright (C) 2015 by authors and Scientific Research Publishing Inc.

This work is licensed under the Creative Commons Attribution International License (CC BY).

http://creativecommons.org/licenses/by/4.0/

(c) (1) Open Access

\section{Abstract}

This paper explores approaches concerning complex forest planning challenges, such as restoration after large-scale disturbances and under climate change. It introduces a new framework that integrates qualitative scenario planning with quantitative multi-criteria decision analysis. This framework allows stakeholders without background in forestry to express their preferences as a set of scenarios that are further assessed for specific forest management goals and activities using multi-criteria models. The assessment of the modelled scenarios created a common understanding for the stakeholders and experts to compare trade-offs between several management options and needed policy choices. The framework was applied in the case study of forest restoration following insect disturbance in British Columbia, Canada. The framework enabled structured stakeholder groups' interactions such as industry, business associations, local and regional governments, and non-governmental organizations to identify potential restoration options. Different community futures were envisioned by two scenarios: one resembling current conditions and standard practices, while another promoting diversification of the forestry sector. The results indicated that each of the scenarios leads to different consequences for the community measured by levels of economic benefits, total harvest volumes and harvest flows over time. The results also show that the developed framework linking scenarios and multi-criteria decision analyses proved crucial to broaden the discussion on relevant species mixes and management practices, and their implications for the community and policy development.

\section{Keywords}

Forest Restoration, Scenario Planning, Multi-Criteria Decision Analyses, British Columbia, Canada, 


\section{Stakeholders' Participation}

\section{Introduction}

Forest management planning is a complex decision-making challenge that needs to account for long time horizons, uncertain biophysical and socioeconomic parameters, and multiple stakeholders' preferences with often conflicting objectives (Food and Agriculture Organization [FAO], 2002; Karjalainen et al., 2003; Leslie, 2009; Khadka et al., 2013). Such complex problems have been typically examined using different approaches-from public consultation, scenario planning, simulation and optimization to multiple-criteria decision analysis (Bolte, et al., 2006; Krcmar \& van Kooten, 2008; Diaz-Balteiro \& Romero, 2008). In supporting the decision-making process, qualitative approaches used in public consultations are just as important as the quantitative methods often applied by forestry professionals (Stirling, 2006; Wollenberg et al., 2000).

Scenario planning is typically used to explore, in a policy-relevant way, the effects of alternative courses of action involving multiple objectives and stakeholders (Swart et al., 2004). Scenario planning is part of the broader set of participatory planning approaches that create a structured process for gathering stakeholders' views and preferences on key challenges, issues, solutions and acceptable trade-offs (Ndubisi, 2002; Pahl-Wostl, 2002; Volkery, et al., 2008). An essential part of this process builds on the effective multi-directional information flows between scientists, decision makers, businesses, and citizens by providing opportunities for all participants to be engaged and by actively producing knowledge and defining the research needs and policy outcomes (Stirling, 2006; Robinson \& Tansey, 2006; Sarewitz \& Pielke, 2007). Such broad engagement of different stakeholders also helps widen perspectives on potential policies and actions by illuminating key issues that might otherwise be missed or dismissed (Khadka et al., 2013).

Scenario planning in forestry is often limited to expert participation in areas such as forest management, timber processing and market forecasts that lacks relevance for stakeholders without background in forestry. The focus of such scenarios is often on simulating diverse forest management options and on predicting their consequences on timber supply, economic costs and benefits, market trends (FAO, 2002; Karjalainen et al., 2003; Leslie, 2009) or simulating impacts of diverse policy choices on forest and corporate management (Kimmins, et al., 2008; Thomson \& Psaltopoulos, 2005). With a focus on broader stakeholder participation, Wollenberg et al. (2000) suggested developing qualitative scenarios to guide community-based forest management. In this context, public participation in scenario development may bring together diverse views, encourage learning and collaboration, might help increasing the acceptance for implementing a management option. However, the interest in stakeholders' participation has been hindered by inconsistency between the quantitative and qualitative domains (Volkery et al., 2008; Pasalodos-Tato et al., 2013), challenging the relevance of scenarios for decision making (Bohunovsky et al., 2011).

Multi-criteria decision analysis (MCDA) is often chosen as the basis for decision support in strategic planning, as it aims to provide a transparent quantitative approach for assessing and balancing conflicting objectives by taking into account the subjective and often qualitative preferences of stakeholders. The MCDA techniques have been classified according to the nature of decision alternatives (actions, strategies, management plans) (Belton \& Stewart, 2002). In the multi-attribute value (MAV) approach, a limited number of decision alternatives is assessed and evaluated with respects to several attributes (criteria, objectives). The MAV methods are based on evaluations of the consequences of each alternative in terms of each attribute. On the other hand, very often the robust decision alternatives are not known in advance. This fact has been instrumental in developing a multiple-objective programming (MOP) approach where several objectives are optimized simultaneously to create a set of decision alternatives that could form a basis for a detailed management plan.

MCDA methods, including both MAV and MOP approaches, have been used in natural resource management including forestry (Mendoza \& Martins, 2006). Kangas \& Kangas (2005) reviewed several MCDA methods applied in forestry. They concluded that simpler methods, like MAV techniques, were more used in the participatory approaches than more sophisticated MOP methods because they were typically easier to understand by participants. Several MAV techniques have been applied for assessing and ranking a finite number of management alternatives (Khadka \& Vacik, 2012). Although more difficult to understand and apply, MOP techniques make better use of all available information and thus provide more detailed guidance on management plans (Pukkala, 
2002). Both exact optimization and heuristics have been used to generate solutions to the MOP problems. Borges et al. (2014) applied linear programming to design a Pareto optimal frontier, while Ducheyne et al. (2006) employed genetic algorithms to solve spatial forest management.

The integration of scenario analysis with multi-criteria analysis has been advocated as an advanced approach for supporting strategic decisions by creating a quantitative platform that accounts multiple goals and qualitative preferences (Montibeller et al., 2006; Bell et al., 2001). Stewart (2005) assessed the advantages of integrating MCDA with scenario planning, especially its ability to compare conflicting goals and highlight potential tradeoffs. Applications of the MCDA combined with scenario planning at the national level were conducted in Austria's energy sector (Kowalski et al., 2009) and in transportation infrastructure planning in the United States (Schroeder \& Lambert, 2011). These applications recognize the challenges in bringing together the preferences of stakeholders with diverse goals and various-often incommensurable-impacts.

In this paper, we specifically focus on gaps in connecting qualitative approaches, namely scenario planning, with quantitative methods, such as the MOP approach into an integrated multi-criteria decisions framework. We analyze a case study of the community of Quesnel in British Columbia, Canada to discuss the opportunities and limitations of the application of the framework while actively involving of stakeholders in forest planning process.

\section{Integrated Scenario Planning and Multi-Criteria Decision Analysis Framework}

Several studies advocating the integration of scenario planning with MCDA have based their analyses on several assumptions: i) future scenarios are well defined; ii) a finite number of alternatives (plans, courses of action) are given and iii) the scenarios are comparable and performance of each alternative can be evaluated in terms of same criteria (Mendoza \& Prabhu, 2005; Montibeller \& Franco, 2010; Stewart et al., 2013). The studies seek to link multi-criteria methods with scenario planning where scenarios serve only as a background to explore the uncertainty issues.

Unlike previous studies, we examine forest planning decisions while acknowledging that several and rather diverse future scenarios are possible, stakeholders have diverse preferences about future actions and that a set of quantifiable criteria is important to transparently compare the scenarios and to guide the planning process. We propose an iterative and interactive framework that integrates scenario development with MCDA. The framework allows both the stakeholders and experts to learn about the problem at hand through an assessment of the alternative forest management goals and activities that will be generated for each scenario using an MOP technique called compromise programming. Because management plans are generated by compromise programming that incorporates the goals and preferences provided by stakeholders, these plans are more likely to be accepted.

The integrated framework that brings together different levels of stakeholder participation during each of its steps are illustrated in Figure 1. The framework starts with a problem-scoping phase to agree on the key methodological steps, form a research team and identify stakeholder groups, including policy-makers, business representatives, community members and forestry professionals/experts (as suggested in Wollenberg et al., 2000; Kok et al., 2006). From the identified stakeholders, a stakeholders' panel is created to review the key methodological steps and provide inputs for the whole process but especially scenario development. At this stage, a brief assessment of available data is conducted to be used in the scenario development.

Scenarios do not attempt to forecast the future; instead, they envision pathways along which the future may develop (Cuginotti et al., 2008). In developing future local scenarios the focus is on specifying time horizons, key goals and on identifying the major activities to realize potential futures. Given that the scenarios would need to be quantified and further compared as per the literature, we suggest focusing on up to four scenarios (Kok et al., 2006; Volkery et al., 2008). This step is designed to gather stakeholder input in a series of workshops during which they also work with input from the research team such as a list of activities with available data. Scenarios developed by stakeholders' groups to bring together diverse goals may contain incommensurable and conflicting criteria (e.g. strong economic development and large-scale pristine environment). This step may also include narrowing down the set of scenarios and goals as one of the possible ways to reduce the cognitive complexity of the decision space.

The next step, quantifying of the scenarios by developing MOP models, is led mostly by researchers, experts and analysts. This step includes collecting data as well as developing the strategic forest-planning models. The data collection inolves gathering information regarding the study area, alternative management practices, ecological and socio-economic concerns and priorities. The models developed within the framework should 


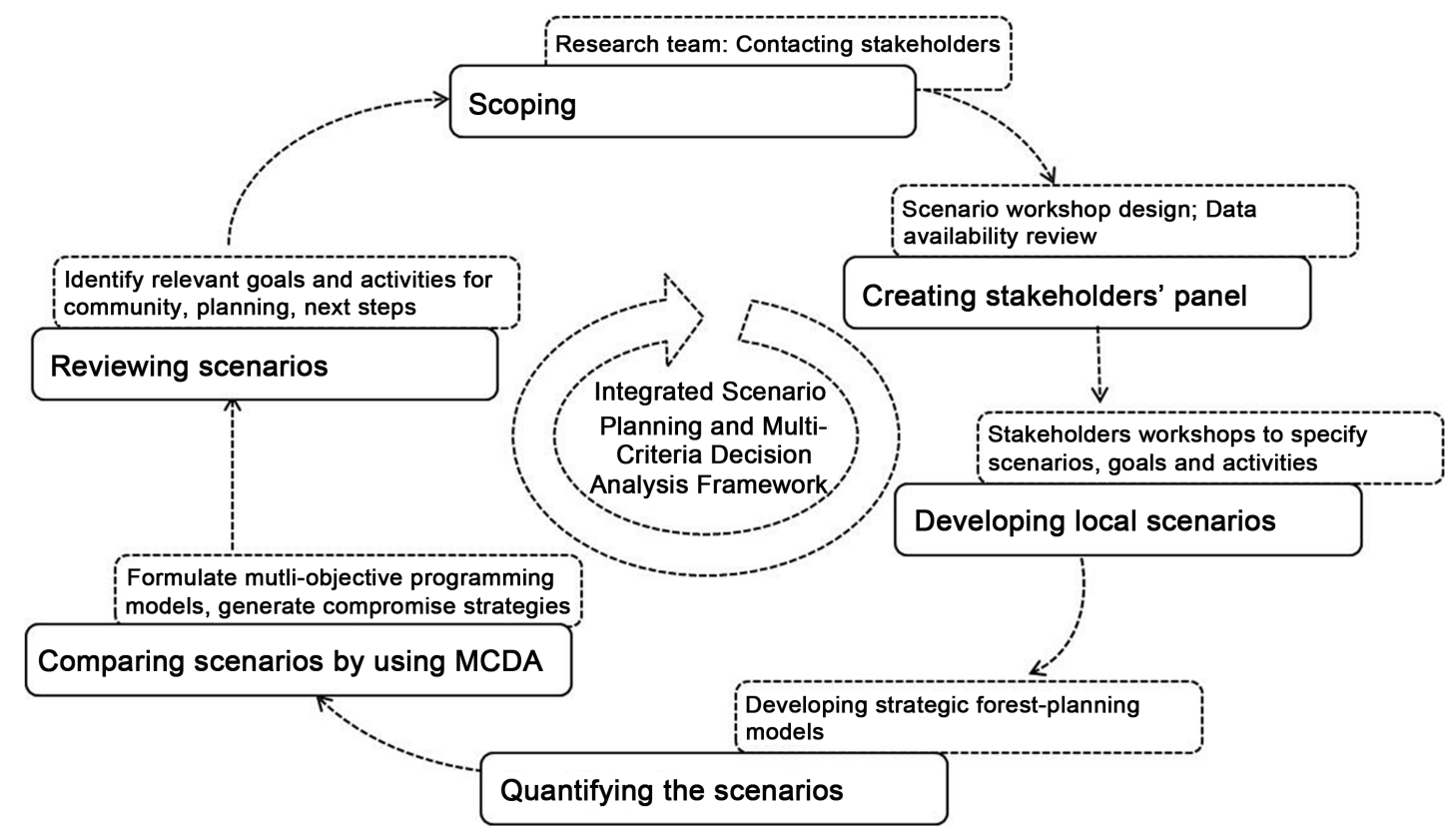

Figure 1. Integrated scenario planning and MCDA framework.

consider only strategic decisions (Montibeller \& Franco, 2011). How these strategic decisions will be executed at the operational level is not examined by the models and will be left to forest managers on the ground. Therefore, the quantification of the scenarios involves coarse spatial and large temporal scales. The models developed in this step need also to be dynamic by taking into account the effect that current decisions have on the future state of the forest.

Then, the step of comparing scenarios by using MCDA is implemented to determine the opportunities for maximizing key goals describing each scenario according to specific measurable criteria by using feasible activities included in each scenario relevant for the study area.

In MCDA, the success of a forest management strategy in accomplishing different goals such as certain level of economic return or species diversification relevant for a specific scenario $s$ is measured using social, economic and environmental criteria (objective functions) (e.g. level of economic returns or deviation for the targeted species composition). Let's assume, a criterion $k$ of a management strategy $x$ is denoted by $C_{k}(x), k \in K$ and a set of feasible forest management strategies is denoted by $X$. If forest planning requires maximization of each criterion, the problem can be formulated as

$$
\operatorname{Max}\left\{C_{k}(x), k \in K\right\} \text { over the set of feasible strategies } x \in X
$$

The use of maximization does not reduce the model application, as minimization is directly converted into maximization by $\operatorname{Min} C(x)=\operatorname{Max}[-C(x)]$.

The program (1) is a formulation of a multi-criteria decision (multi-objective optimization) problem which means that all criteria $C_{k}(x), k \in K$ are to be maximized simultaneously. In real life, criteria are often in conflict and in that case there are no feasible strategies that simultaneously provide values for all criteria. Instead, in multi-objective optimization we search for Pareto-optimal strategies. A strategy is called Pareto-optimal (nondominated, efficient) if none of the criteria values can be improved without degrading some of the other criteria values. One way to find solutions to multiple-objective programming problems is to construct an aggregate criterion (objective) to be optimized. Minimizing a distance between the current criteria values and the target values is a basis for compromise programming and similar MCDA techniques (Romero et al., 1987). Compromise programming has been used for forest management with timber, carbon, biodiversity and socioeconomic objectives (Krcmar et al., 2005; Krcmar \& van Kooten, 2008), for harvest scheduling and paper industry problems (Diaz-Balteiro et al., 2009; Diaz-Balteiro et al., 2011). 
Let $d_{k}(x)=\frac{C_{k}^{*}-C_{k}(x)}{C_{k}^{*}-C_{k^{*}}}, k \in K$ denote the distance of the current criterion value $C_{k}(x)$ from its best value $C_{k}^{*}(x)$, normalized by the range of values $C_{k}^{*}-C_{k}$. The compromise solutions to the MCDA model are obtained by solving

$$
\min _{x \in X} L_{\pi}(w, x)=\left\{\sum_{k \in K} w_{k}^{\pi}\left[d_{k}(x)\right]^{\pi}\right\}^{1 / \pi}
$$

for different values of $\pi$ and $w$; weights $w_{k} \in[0,1], k \in K ; \sum_{k \in K} w_{k}=1$ reflect the relative importance of the criteria, and the choice of distance parameter $\pi(1 \leq \pi \leq \infty)$ indicates a particular form of conflict management between the competing criteria. For $\pi=1$, the problem becomes

$$
\min _{x \in X} S(w, x)=\min _{x \in X} \sum_{k \in K} w_{k} d_{k}(x)
$$

The forest management strategy that minimizes the weighted sum of $d_{k}(x)$ over set $X$ will be called the compromise strategy.

In the trade-off assessment phase a set of criteria values is calculated at different compromise strategies for each scenario $S_{i}$, where $i$ is an index from the set $I$. The criteria values are presented in a tabular format, where $c_{i j k}=C_{k}\left(a_{j}^{i}\right),[i \in I, j \in J, k \in K]$ is the value of criterion $C_{k}$ calculated at the strategy $a_{j}^{i}$ under the scenario $S_{i}$ (Table 1 ).

The criteria values presented in Table 1 correspond to various (compromise) strategies obtained by solving program (2) for the different combinations of weights $w_{k}$. To generate a management strategy that maximizes the criterion $C_{k}(x)$, we solve the program (2) with the corresponding weight $w_{k}=1$ and the remaining weights equal 0 . Other compromise strategies are obtained by minimizing the weighted sums in (2) with $w_{k}>0$ under different scenarios $S_{i}$. Thus, Table 1 allows stakeholders to examine the range of values for each criterion, which further allows for comparing and identifying trade-offs between and within each scenario.

The last phase is reviewing the scenarios with the help of stakeholders. The aim of this review is not only to compare the scenarios and their consequences but also to identify the relevance of the outcomes for policy and planning. The outcomes of the multi-criteria analysis help the stakeholders better understand the problem and the trade-offs between the criteria values associated with different management strategies and scenarios.

If stakeholders feel that none of the strategies under the scenarios considered is acceptable in terms of all criteria, in the next iteration, the stakeholders' panel can expand the original set of scenarios. It is also possible for the stakeholder panel to reduce the scenario set to only one scenario but to expand the criteria set under that scenario.

The iterative process will end when the stakeholders feel that one or more plans under the specific scenario are acceptable in terms of all criteria and/or they are in an agreement about the preferred scenario.

\begin{tabular}{cccccc} 
Table 1. Criteria values. & & & & \\
\hline & & Scenario $S_{i}$ & & & \\
\hline Strategy & $a_{1}^{i}$ & $\ldots$ & $a_{j}^{i}$ & $\ldots$ & $a_{J}^{i}$ \\
Criterion & & & & & \\
$C_{1}$ & $c_{i 11}$ & $\ldots$ & $c_{i j 1}$ & $\ldots$ & $c_{i j 1}$ \\
$\ldots$ & & & & & \\
$C_{k}$ & $c_{i 1 k}$ & & $c_{i j k}$ & & $c_{i j k}$ \\
$\ldots$ & & & & & \\
$C_{K}$ & $c_{i 1 K}$ & & $c_{i j k}$ & & $c_{i j k}$ \\
\hline
\end{tabular}




\section{Application of the Framework to Forest Planning after Insect Disturbance in British Columbia, Canada}

A recent mountain pine beetle (MPB) infestation in British Columbia (B.C.) is considered the largest forest insect epidemic in Canada's history and is attributed to decades of fire suppression practices, restoration strategies and climate variability (B.C. MoF, 2010). The epidemic has challenged the role of forestry in community economic development (Kumar et al., 2005; Kimmins et al., 2008), including future forest management decisions and how these decisions might meet diverse community needs (MacKendrick \& Parkins, 2005). Several government restoration programs have focused on the short-and medium-term challenges, with emphasis on strengthening the competitiveness of the forestry sector; economic diversification in the affected areas, including non-timber products, recreation, mining and identifying new management approaches to increase forest resilience (Government of B.C., 2006; FFEI, 2008).

Restoration of infected forestlands has attracted a great deal of attention, not only from forest managers and environmentalists but also from members of forest-dependent communities and First Nations worried about employment prospects and community stability. Given this wide range of stakeholder interests and preferences, the restoration of forests affected by MPB represents a complex policy challenge with potentially conflicting social, economic and ecological concerns (Kimmins et al., 2008). The proposed framework was applied to a case study of Quesnel in B.C. to explore future scenarios based on diverse stakeholder preferences, to quantify and compare outcomes within and between the scenarios in order to create a platform for a forest restoration planning process. The case study analysis was conducted from 2008 to 2011.

The Quesnel Timber Supply Area (TSA), located in the central interior of B.C., covers approximately 2 million hectares (ha). The forest industry is the most important sector in the area, both in terms of employment and community income. The forestry sector contributes at least 30 per cent of the direct and indirect income of the Quesnel community (QCEDC, 2008). The community has recently experienced a boom in wood processing, mainly due to a large amount of infested wood that had to be harvested and processed within a timeframe dictated by the shelf life of the wood. Several analyses have warned about an impending mid-term gap in timber supply (Government of B.C., 2006). Other studies have shown that the MPB infestation has put pressure on community capacity to respond to stress and to make decisions about future development (MacKendrick \& Parkins, 2005; QCEDC, 2008). Based on a community survey, residents favour multiple-facet forest management and non-timber forest products that will ensure employment and community stability (Harshaw et al., 2006) ${ }^{1}$.

\subsection{Scoping of the Project Focus and Ways of Participation}

The steps included forming a research/expert team of five experts (including the authors of this paper) with diverse expertise in areas such as community development, scenario development, forest sector and ecosystem management. The main task of the research/expert team was to lead the scenario development process, data collection and quantification and review of the scenarios. In the context of the case study, the stakeholders' groups included representatives of forestry companies and business organizations, federal and provincial policy-makers, municipal leaders, forestry experts, community development experts and representatives of civil society organizations active in the area. In terms of choosing specific stakeholders according to the criteria suggested in Tompkins et al. (2008) we focused on those that have a direct personal stake (residents, forestry and non-forestry-related businesses, municipal officials, organizations focusing on natural resource management in the area) and those that have a role in forest management through policy (i.e., provincial and federal agencies). Existing contacts were used to identify other stakeholders.

\subsection{Creating a Stakeholder Panel}

We created a stakeholders' panel of eight people out of the identified 42 stakeholders. Working with the panel, the research team assessed the data availability and identified a set of key goals for which data were available and that could be included in quantitative MCDA. While the stakeholders had the opportunity to select any goal for the scenarios, they were informed about those that can be quantified.

The stakeholder panel helped design the scenario development workshops by suggesting the number and the length of the workshops, location, and types of workshop activities. Members of the panel had an opportunity to

\footnotetext{
${ }^{1}$ Additional information about the case study area and key datasets is available in the Appendix.
} 
participate in the workshops, as most of them were interested in being active participants in scenario development. The panel was also consulted during the other steps of the framework.

\subsection{Developing Local Scenarios}

Two scenario development workshops (with 15 participants each) were held in the community. In the plenary session of the workshops, panel members provided an overview and discussed the past and present status of the local economy and well-being, the MPB infestation and forestry-sector performance. The workshop then focused on future scenarios, starting with identifying the time horizons, types of scenarios and specifying key characters of sectors within the scenario such as forestry, agriculture, tourism and education. It then moved to describing key goals and activities (Table 2). The stakeholders were advised that creating up to four scenarios are generally suggested in the literature (Kok et al., 2006; Volkery et al., 2008). The goals were presented in neutral terms, such as annual harvest of timber and diversification of land use across sectors, and in a plenary session participants had the opportunity to specify the desired trend (e.g., maintaining or increasing or decreasing of annual harvest). To prioritize the specified goals and activities, the participants were asked to score each of the specific goal/activity according to their relevance for each of the scenarios. The results were reviewed in a plenary session.

Despite their varying profiles, workshop participants gave highest priority to diversification of the regional economic base. In a discussion about the potential scenarios and goals, the participants emphasized the importance of developing sectors beyond forestry, including tourism and agriculture. However, the availability of data narrowed the focus to comparing goals and activities within the forestry sector and thus priorities such as improving employment in tourism and increasing the harvest of non-timber forest products were excluded from the analyses. In narrowing the focus to forestry, participants identified two distinct scenarios for the community's future: "a strong forest sector" and "forest resilience/economic diversification". The "strong forest sector" Scenario I was considered a status quo scenario, since it represented current practices, including a regeneration strategy that closely followed the current tree species composition; however, it also aimed to create more highvalue forest products. The "forest resilience/economic diversification" Scenario II emphasized diversification of the forest landscape as well as that of the forest sector. Participants reported that they preferred to work with only two distinctly different scenarios to allow clear comparison between the status quo and the scenario that was discussed informally between the stakeholders.

For each of the scenarios, three goals were identified along with several activities (listed in Table 3). Under Scenario I, which represents the vision of a strong forestry sector, both economic and timber supply goals were considered. For the economic goal, we formulated the criterion of total net discounted returns from forest management over the planning horizon. To achieve this criterion, the forestry strategy calls for aggressive harvest of profitable stands early in the planning horizon. The timber supply goal addresses concerns related to adequate supply of fibre for mills and satisfying contractual obligations with the province and industry. The latter goal is typically accomplished by a criterion on maintaining the even flow of harvest volume over time. We couple this even flow with the maximization of cumulative harvest volume because this combination drives fibre supply as high as possible.

Table 2. Goals and activities used to quantitatively describe scenarios.

\begin{tabular}{|c|c|c|}
\hline Socioeconomic goals & Environmental goals & Activities \\
\hline \multicolumn{2}{|c|}{ Increase/maintain/decrease } & Manage \\
\hline $\begin{array}{l}\text { - } \text { Total employment } \\
\text { - } \text { Employment in forest sector } \\
\text { - } \text { Annual income per capita } \\
\text { - } \text { Forest sector sales revenues } \\
\text { - } \text { frovincial and federal government revenues } \\
\text { - Annual harvest of timber } \\
\text { - } \text { Annual harvest of non-timber forest products }\end{array}$ & $\begin{array}{l}\text { - Diversify land use across sectors } \\
\text { - Diversify forests by species and } \\
\text { age structure } \\
\text { - Area of protected forests } \\
\text { - }\end{array}$ & $\begin{array}{l}\text { - Lodgepole pine } \\
\text { - Tree species other than pine } \\
\text { - Native }{ }^{\text {a }} \text { tree species for bio-energy production } \\
\text { - Non-native }{ }^{b} \text { tree species for bio-energy production } \\
\text { - Native tree species that could adapt to future climate } \\
\text { - Non-native tree species that could adapt to future climate } \\
\text { - None tree species more resistant to pest attacks }\end{array}$ \\
\hline
\end{tabular}

${ }^{\mathrm{a}}$ Indicates native to the region; ${ }^{\mathrm{b}}$ Indicates non-native to the region. 
Table 3. Key goals, criteria and activities within the two identified scenarios.

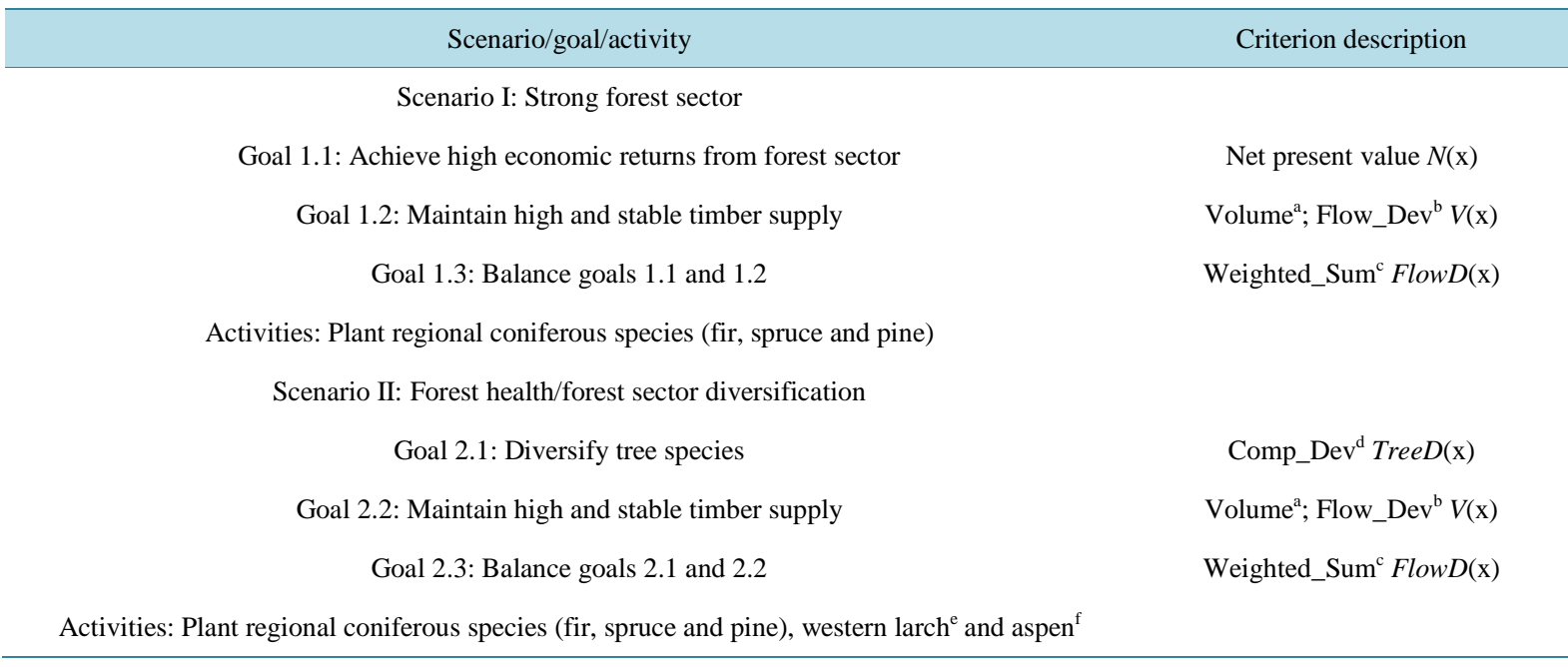

Notes: fir: Pseudotsuga menziesii; spruce: Picea (excluding P. mariana); pine: Pinus contorta; western Larch: Larix occidentalis; aspen = Populus sp. ${ }^{\mathrm{a}}$ Cumulative harvest volume over the time horizon; ${ }^{\mathrm{b}}$ Deviation from even harvest flow; ${ }^{\mathrm{c}}$ Weighted sum; ${ }^{\mathrm{d}}$ Deviation from target tree species abundance; ${ }^{\mathrm{e}}$ Tree species suitable for adaptation to the regional climate change; ${ }^{\mathrm{f}}$ Fast-growing species suitable for multiple uses.

Scenario II represents a vision of a healthy forest and a diversified forestry sector. Different approaches to achieve this vision are possible. From the perspective of the recent MPB epidemic (B.C. MoF, 2008), we consider both the age and species diversity of the forest and diversification of the fibre supplied to the manufacturing industry. The criterion for these goals then also focuses on the difference compared to target tree species composition.

The planning horizon was also determined at the workshop. Several predictions of the impact of MPB epidemic on timber supply concluded that a large drop in timber harvest will start occurring around 2020 (FFEI, 2008). The workshop participants expressed concerns about focusing on such a short-term time horizon. Although addressing this looming disaster was seen as highly relevant for the local economy, participants working in forestry were interested in longer-term time horizons, i.e., over the next 50 to 100 years. Because of the long rotation age, we have conducted quantitative analyses over the 200-year planning horizon and then extracted the results relevant for the choosen short-to-medium period.

\subsection{Quantifying the Scenarios}

Working with the identified goals, two models were developed to simulate the potential changes in the forest restoration given the goals and activities specified for the two scenarios. For each of the scenario, the forest restoration models are optimized for the chosen criteria by using a series of multi-criteria linear programs. The model development included taking into account the preferred species and management practices for the restoration, prioritized for each of the scenarios in the previous steps as well as other key characteristics of the forest cover such as age, site or species in the case study area. Below we provide an overview of the two models developed and the types of data used.

Forest attributes (i.e. species, age and site class) are aggregated into management strata $m \in M$, where $M$ is the set of management strata, $P(m, t)$ is a set of management treatments appropriate to stratum $m$ in period $t \in T$, where $T$ is the set of decadal periods over the planning horizon. Management treatments include various combinations of salvage harvest and renewal activities. A forest management strategy $x=x_{m p t}$ represents the area (in ha) of forestland of stratum $m$ managed by treatment $p$ in period $t$. The set $X$ of feasible forest management staretgies includes technical constraints on land availability, harvest, renewal and silviculture activities, the initial and terminal timber inventories. Details of the case study including description of the study area, management treatments, timber supply and economic parameters are provided in the Appendix.

Let $v_{\text {mpt }}$ denote the merchantable volume in $\mathrm{m}^{3}$ from a hectare of stratum $m$ managed by treatment $p$ in period $t, n v_{m p t}$ is the net revenue in \$ per hectare of stratum $m$ managed by treatment $p$ in period $t$ and $r$ is the discount rate. 
Then, $\operatorname{Vol}_{t}(x)=\sum_{m \in M} \sum_{p \in P(m, t)} v_{m p t} x_{m p t}$ denotes the harvest volume in period $t$ and $V(x)=\sum_{t \in T} V_{t} l_{t}(x)$ is the cumulative harvest volume over the horizon. The discounted net revenue $N(x)$ from forest management over the horizon is defined as $N(x)=\sum_{m \in M} \sum_{t=1}^{T} \sum_{p \in P(m, t)}(1+r)^{-t \times 10} n v_{m p t} x_{m p t}$.

The maximum absolute difference between harvest volumes in subsequent periods is defined as Flow $D(x)=\max _{t}\left|\operatorname{Vol}_{t+1}(x)-\operatorname{Vol}_{t}(x)\right|$ and reflects the range of change in timber supply over time. If maintaining the stable timber supply over the horizon is a management goal, then $\operatorname{Flow} D(x)$ is to be minimized.

As already mentioned, in Scenario I the economic goal is coupled with the timber supply goal and the multi-criteria model is formulated as:

\begin{tabular}{lcc}
$(\mathrm{ScI}-\mathrm{MCM})$ & \\
\hline$(\mathrm{NPV})$ & $\operatorname{Max} N(x)$ \\
$(\mathrm{VOL})$ & $\operatorname{Max} V(x)$ \\
$(\mathrm{EVEN})$ & $\operatorname{Min} F \operatorname{low}(x)$ \\
& subject to & $x \in X$. \\
\hline
\end{tabular}

Scenario II addresses both forest health and diversification of the forestry sector. To achieve the forest health goal, in the light of recent MPB epidemic in BC and imminent climate change, several studies promoted management strategies that would change the current age and tree species abundance (Beardmore \& Winder, 2011). A recent study projected a significant shift of tree species in British Columbia as a result of changing climatic conditions and an increasing occurrence of Douglas fir and western larch in the areas north of their current occurrence (Hamann \& Wang, 2005). Following the workshop conclusions and the literature review, planting tree species adaptable to climate change was added as an alternative to planting regional tree species. In addition to planting coniferous and deciduous tree species currently occurring in the area, a specific restoration option included planting western larch (Rehfeldt \& Jaquish, 2010).

Diversity of tree species in the region was used as a proxy for modelling forest health in this paper. The corresponding criterion is defined relative to a desired tree species abundance that will be called the "target" abundance. The target for this study was established by relying on a combination of expert opinions and public expectations using the results of the workshops conducted in other regions of British Columbia affected by MPB (Harshaw et al., 2006; B.C. MoF, 2008).

Under Scenario II, the models are developed to search for strategies that meet multiple goals while aiming to change the current tree species composition and abundance. We start by partitioning the strata set $M$ by tree species $s \in S$, where $S$ is the set of tree species. Denote by $M_{s} \subseteq M$ a partition of $M$ by species $s$. If $A_{s}(x)$ is the actual abundance of species $s$ at the management strategy $x$, and $T A_{s}$ is the target abundance of tree species $s$, then $\operatorname{Tree} D(x)=\max _{s}\left|A_{s}(x)-T A_{s}\right|, s \in M_{s}$ represents the difference between the actual $C_{s}(x)$ and the target $T C_{s}$ abundance. Both $A_{s}(x)$ and $T A_{s}$ are expressed in terms of portions (\%) of the land base area. When the target abundance for all species is fully achieved, $\operatorname{Tree} D(x)$ is zero. In all other cases, $\operatorname{Tree} D(x)$ reflects the deviation from the target abundance. If meeting the target tree abundance is the goal of forest renewal, then $\operatorname{Tree} D(x)$ is to be minimized. For Scenario II, the multi-criteria model is formulated as

(Sc II-MCM)

\begin{tabular}{cc}
\hline (DIVERS) & $\operatorname{Min} \operatorname{TreeD}(x)$ \\
(VOL) & $\operatorname{Max} V(x)$ \\
(EVEN) & $\operatorname{Min} \operatorname{FlowD}(x)$ \\
subject to & $x \in X$. \\
\hline
\end{tabular}

The meanings of criteria functions $V(x)$ and $F l o w D(x)$ are the same as for the Scenario I model. 


\subsection{Comparing Scenarios Using MCDA}

For each scenario, we generated several single-criterion strategies and one multi-criteria strategy by solving a series of linear models using the CPLEX solver on the GAMS platform (Brooke et al., 2004). We calculated several indicators for each strategy and used them to assess the economic, timber supply and species diversity impacts.

To generate single-criterion management strategies we optimized each criterion individually. Under Scenario I, three strategies N1, V1 and E1 were generated by maximizing $N(x)$, maximizing $V(x)$ and minimizing Flow $D(x)$, respectively. Similarly, single-criterion strategies D2, V2 and E2 were generated by minimizing TreeD(x), maximizing $V(x)$ and minimizing Flow $D(x)$, respectively under Scenario II. Then we determined the compromise S1 and S2 strategies by minimizing the weighted sums in Equation (2) under the respective Scenario I and Scenario II. Table 4 presents the criteria values for each strategy. For example, the N1 strategy maximizes the financial benefits $N(x)$ under Scenario I. The components of N1 column are calculated as the values of the corresponding criteria at N1 (Table 5).

The two scenarios show significant differences when compared in terms of the economic and timber supply values. We specifically use net present value $(\mathrm{N})$, cumulative volume $(\mathrm{V})$, and maximum deviation from stable harvest flow (FlowD). All criteria are in conflict with the strongest disagreement presented between economic and timber supply benefits. There is also significant conflict in simultaneously achieving the high volume and stable timber supply over the time horizon. Under Scenario I, the N1 strategy leads to the worst level of cumulative harvest. To attain the net present value of CAD\$ 1.186 billion, the cumulative volume drops to 280 million $\mathrm{m}^{3}$, or 85.4 per cent of its highest value of 384 million $\mathrm{m}^{3}$. On the other hand, the Scenario II volume maximizing V2 strategy is in strong conflict with the even flow E2 strategy and leads to a deviation of 40 million $\mathrm{m}^{3}$ from stable harvest per decadal period. Another significant conflict occurs between the tree species diversity and timber supply goals. The D2 strategy results in the lowest cumulative harvest, of 178.6 million $\mathrm{m}^{3}$ (only 46.5 per cent of 384 million $\mathrm{m}^{3}$, the highest cumulative harvest).

Overall, the single-criterion strategies result in large tradeoffs between the criteria values across both scenarios. Based on the feedback from the stakeholder panel, these tradeoffs were clearly unacceptable. To balance the conflict among the criteria for Scenario I, we constructed the compromise S1 strategy by minimizing the weighted sum (2), with equal weights associated to all criteria. While the financial and cumulative timber supply achieved by the S1 strategy are both quite high, there are significant deviations from even flow between the periods. The compromise strategy S2 under Scenario II was relatively successful in meeting all the goals except for the financial outcome.

Table 4. Species abundance ${ }^{\mathrm{a}}$ for several strategies.

\begin{tabular}{cccccccccccc}
\hline & \multicolumn{3}{c}{ Scenario I strategies } & \multicolumn{4}{c}{ Scenario II strategies } \\
\hline Species & N1 & V1 & E1 & S1 & Target & Initial & D2 & V2 & E2 & S2 \\
\hline Fir & 4.9 & 4.9 & 4.9 & 4.9 & 15 & 4.9 & 15 & 4.9 & 4.9 & 13 \\
Spruce & 13.1 & 15.2 & 22.3 & 16.6 & 15 & 12.9 & 15 & 13.6 & 12.9 & 15 \\
Pine & 77.9 & 75.9 & 68.5 & 74.5 & 45 & 78.2 & 46 & 45.2 & 44.5 & 50 \\
Aspen & 4 & 4 & 4 & 4 & 10 & 4 & 10. & 16.7 & 32.3 & 7 \\
Larch & 0 & 0 & 0 & 0 & 15 & 0 & 14 & 19.6 & 5.4 & 15 \\
\hline
\end{tabular}

${ }^{\mathrm{a}}$ Species abundance expressed as portion (\%) of the forestland.

Table 5. Criteria values for several strategies-the best criteria values are presented in bold while the worst values are under$\underline{\text { lined. }}$

\begin{tabular}{|c|c|c|c|c|c|c|c|c|}
\hline \multirow[b]{2}{*}{ Criteria values } & \multicolumn{4}{|c|}{ Scenario I strategies } & \multicolumn{4}{|c|}{ Scenario II strategies } \\
\hline & N1 & V1 & E1 & S1 & D2 & V2 & E2 & $\mathrm{S} 2$ \\
\hline$N$ (million \$) & 1186 & 1129 & $\underline{797}$ & 1,033 & $\underline{348}$ & 943 & 502 & 761 \\
\hline$V\left(\right.$ million $\left.\mathrm{m}^{3}\right)$ & $\underline{280}$ & 328 & 294 & 323 & $\underline{179}$ & 384 & 305 & 382 \\
\hline FlowD (million $\mathrm{m}^{3}$ ) & $\underline{38}$ & 37 & $\mathbf{0}$ & 9 & 26 & $\underline{40}$ & $\mathbf{0}$ & 3 \\
\hline
\end{tabular}


Additional differences between the two scenarios are evident when the scenarios are compared in terms of the tree species abundance (Table 4). Not surprisingly, all Scenario I strategies, except for the E1 strategy, resulted in tree species abundance similar to the initial species abundance. An unexpected result emerges for the E1 strategy; to provide a stable harvest flow, the E1 strategy requires planting more spruce, which leads to reduced planting of pine and thus allows for a more diverse landscape.

As suggested by stakeholders, Scenario II was designed around planting combinations of several tree species to mitigate future risks related to natural disturbances and also to generate the fibre supply for a diversified forest industry. The D2 and S2 strategies recommend increased planting of fir, spruce and western larch, while the V2 strategy implies planting large areas of larch early in the time horizon in order to enable its harvest later in the horizon. Instead, the E2 strategy relies mostly on planting aspen. Not only does aspen help increase species diversity, its fast growth contributes to a steady harvest flow over time.

\subsection{Reviewing Scenarios}

The scenarios review was conducted in a workshop setting, where the outcomes for each scenario were compared and trade-offs presented. At this stage the combined consideration of qualitative and quantitative components in the scenario development was particularly useful.

Workshop participants found it interesting to realize that none of the scenarios was superior in terms of all criteria values. The applied MCDA helped participants see how conflicting goals could be balanced. The conflicts were described to participants by comparing the criteria values across the scenarios for the key management strategies. Economic benefits, expressed in terms of cumulative discounted net return over the planning horizon, are significantly higher in Scenario I than in Scenario II across the corresponding strategies. At the same time, total harvest volumes across the same strategies are slightly higher in Scenario II than in Scenario I. In terms of harvest flow over time, Scenario II scores better than Scenario I, in particular for the compromise strategy. One of the reasons for reduced net present value under Scenario II is the harvest of low-priced aspen. Finally, achieving both the diversification and even-flow goals caused a reduction in the early-period harvest volume; this further contributes to a reduction in the discounted net returns.

Although Scenario II seemed promising in meeting several goals, no strategy was found that would be acceptable in terms of all criteria. For the next steps in the case study, the participants felt that an economic criterion needed to be included into MCDA under Scenario II. They also suggested linking the outcomes of our analysis with an on-going forest planning process conducted by forestry companies and government agencies. This would allow exploring the restoration treatments with additional tree species.

\section{Discussion and Conclusions}

The presented case study, including the applied methodology and the developed scenarios and their comparison, provides a guidance for forest-based communities on how to bring together diverse groups of stakeholders and compare their preferences on the forestry's future in the region. The applied methodology also provided opportunities for capacity building for the involved stakeholders regarding the potential restoration options, relevant tree species and management practices. Furthermore, one of the crucial outcomes of the study was about creating opportunities for professionals in the forestry sector to explore alternative choices for renewal strategies by gaining support of the local stakeholders.

In the presented case study and other attempts to forest planning challenges, stakeholders may have different preferences for the future and how to achieve them compared to conventional views. The scenario planning was a useful tool to frame the stakeholder's interactions in a task-oriented manner focused on identifying future scenarios, goals and activities (as also suggested in Pasalodos-Tato et al., 2013). Identifying these aspects of forest restoration with stakeholders as well as quantifying their preferences by using MCDA increased the legitimacy of applied process as it created an acceptable baseline instead of relying on the research team to use their data and models to create future scenarios. The process enabled the active engagement of all stakeholders (even nonforest experts) in bridging the qualitative to the quantitative domain because the goals and activities were understandable for lay audiences (as it was done for example in Kowalski et al., 2009; Volkery et al., 2008). The challenge in the approach we undertook is in the substantial up-front work that must be done before the stakeholders begin the actual scenario development to identify for what types of issues data are available and for the stakeholders to accept that not all their preferences can be quantified because of lack of data. 
We formulated several criteria for each scenario to measure the impacts of restoration strategies. MCDA provided a useful tool, both for generating management strategies that can serve as pathways toward preferred community futures and for quantifying the trade-offs among conflicting criteria along those pathways. The focus on the forestry sector, for which data have been readily available, enabled us to perform a trade-off analysis. However, we excluded several concerns that were of interest to participants because of missing data and insufficient time for development of a cross-sectoral model. These concerns included the roles of tourism, agriculture and education. For future work, it would be important to start exploring the possibilities of integrating some of these sectors to identify additional revenues, employment and a more diversified economic basis for the community.

The stakeholder-driven scenario planning process has a "problem-based” focus on restoration after MPB that recognizes the importance of diverse views regarding potential actions. Regardless of the on-going and projected future changes in the areas affected by MPB, forestry will likely remain a dominant economic sector in the region (B.C. MoF, 2008). However, tree species, management practices and production methods in the near future may change significantly, and many stakeholders lack knowledge of potential alternative actions and their consequences. By defining a context of analysis, scenario planning provided opportunities for capacity-building and improve the knowledge of diverse stakeholders' by introducing information about new species, different management practices and business models to stakeholders for consideration when describing the scenarios through goals and actions.

One of the crucial results of the case study was creating opportunities for professionals in the forestry sector to explore alternative choices for renewal strategies. Many of the forestry experts - constrained by accepted practice within their industry - found support in the stakeholders' groups that contributed to defining different alternatives compared to conventionally considered practices. Thus the results created opportunities to broaden the discussion about long-term forest policy and goals among forest professional as well. Recent policy and strategic guidance provided at different levels of government acknowledges the need for longer-term visions (B.C. MoF, 2008). The outcomes of the process presented in this paper indicate what a long-term pathway may look like. Further research and investigation of a range of options, including the use of community-specific data regarding other economic sectors, should take place. Another factor contributing to the complexity of forest renewal is uncertainty regarding climate change and its impact on forest ecosystems. Targeted impact assessment under different climate scenarios is needed to ensure that the species are suited for changed environmental conditions.

Finally, the approach also pointed out a number of broader challenges for research and policy-making in forestry. In terms of future needs, it includes exploring ways for stronger integration of socioeconomic and environmental criteria into narrowly focused sectorial forestry-based modelling that cannot be effectively linked with the multi-sectorial focus of local and regional policies and planning processes. This could include developing standardized and tested methodologies that could be easily taken up by communities to bring a multi-sectorial perspective into resource planning allowing a basis for comparison and learning across communities.

\section{Acknowledgements}

This work was funded by the Government of Canada through the Mountain Pine Beetle Initiative, a program administered by Natural Resources Canada-Canadian Forest Service. Publication does not necessarily signify that the contents of this paper reflect the views or policies of Natural Resources Canada-Canadian Forest Service.

The authors wish to thank Phil Winkle and the Quesnel TSA Timber Supply and Environmental Values Mitigation Committee for generously helping to acquire data. We thank all of the Quesnel workshop participants for their contributions.

\section{References}

Beardmore, T., \& Winder, R. (2011). Review of Science-Based Assessments of Species Vulnerability: Contributions to Decision-Making for Assisted Migration. The Forestry Chronicle, 87, 745-754. http://dx.doi.org/10.5558/tfc2011-091

Bell, M. L., Hobbs, B. F., Elliott, E. M., Ellis, H., \& Robinson, Z. (2001). An Evaluation of Multi-Criteria Methods in Integrated Assessment of Climate Policy. JMCDA, 10, 229-256.

Belton, V., \& Stewart, T. J. (2002) Multiple Criteria Decision Analysis: An Integrated Approach. Dordrecht: Kluwer. http://dx.doi.org/10.1007/978-1-4615-1495-4 
Bohunovsky, L., Omann, I., \& Jäger, J. (2011). Participatory Scenario Development for Integrated Sustainability Assessment. Regional Environmental Change, 11, 271-284. http://dx.doi.org/10.1007/s10113-010-0143-3

Bolte, J. P., Hulse, D. W., Gregory, S. V., \& Smith, C. (2006). Modeling Biocomplexity: Actors, Landscapes and Alternative Futures. Environmental Modelling \& Software, 22, 570-579. http://dx.doi.org/10.1016/j.envsoft.2005.12.033

Borges, J. G., Garcia-Gonzalo, J., Bushenkov, V. A., McDill, M. E., Marques, S., \& Oliveira, M. M. (2014). Addressing Multi-Criteria Forest Management with Pareto Frontier Methods: An Application in Portugal. Forest Science; in Press. http://dx.doi.org/10.5849/forsci.12-100

British Columbia Ministry of Forests and Range (B.C. MoF) (2008) Sustaining Communities: 2006-2011 Mountain Pine Beetle Action Plan. Progress Report. Victoria: British Columbia Ministry of Forests and Range.

British Columbia Ministry of Forests and Range (B.C. MoF). (2007) TIPSY. www.for.gov.bc.ca/hre/gymodels/TIPSY/index.htm

Brooke, A., Kendrick, D., Meeraus, A., \& Raman, R. (2004). GAMS: A User’s Guide. Washington DC: GAMS Development Corporation.

Cuginotti, A., Miller, K. M., \& van der Pluijm, F. (2008). Design and Decision Making: Backcasting Using Principles to Implement Cradle-To-Cradle. Karlskrona: School of Engineering Blekinge Institute of Technology.

Diaz-Balteiro, L., \& Romero, C. (2008). Making Forestry Decisions with Multiple Criteria: A Review and an Assessment. Forest Ecology and Management, 255, 3222-3241. http://dx.doi.org/10.1016/j.foreco.2008.01.038

Diaz-Balteiro, L., Bertomeu, M., \& Bertomeu, M. (2009). Optimal Harvest Scheduling in Eucalyptus Plantations: A Case Study in Galicia (Spain). Forest Policy and Economics, 11, 548-554. http://dx.doi.org/10.1016/j.forpol.2009.07.005

Diaz-Balteiro, L., Voces, R., \& Romero, C. (2011). Making Sustainability Rankings Using Compromise Programming. An Application to European Paper Industry. Silva Fennica, 45, 548-554. http://dx.doi.org/10.14214/sf.103

Ducheyne, E. I., De Wulf, R. R., \& De Baets, B. (2006). A Spatial Approach to Forest-Management Optimization: Linking GIS and Multiple Objective Genetic Algorithms. International Journal of Geographical Information Science, 20, 917-928. http://dx.doi.org/10.1080/13658810600711287

Food and Agriculture Organization (FAO) (2002). FAO Global Forest Products Outlook Study. Rome: FAO.

Forest Ecosystems Solutions Ltd. (FESL) (2008). Economic Operability Assessment and Priority Classification in MPB Impacted Areas in the Quesnel Timber Supply Area. Vancouver: FESL.

Future Forest Ecosystems Initiative (FFEI) (2008). Future Forest Ecosystems Initiative: Strategic Plan. Victoria: British Columbia Ministry of Forests.

Government of British Columbia (2006). British Columbia’s Mountain Pine Beetle Action Plan 2006-2011. Victoria: Government of B.C.

Hamann, A., \& Wang, T. (2005). Models of Climatic Normals for Genecology and Climate Change Studies in British Columbia. Agricultural and Forest Meteorology, 128, 211-221. http://dx.doi.org/10.1016/j.agrformet.2004.10.004

Harshaw, H. W., Sheppard, S. R. J., Kozak, R. A., \& Maness, T. C. (2006). CANFOR Sustainable Forest Management Public Opinion Survey 2005/2006. Vancouver: Faculty of Forestry, University of British Columbia.

Kangas, J., \& Kangas, A. (2005). Multiple Criteria Decision Support in Forest Management-The Approach, Methods Applied, and Experiences Gained. Forest Ecology and Management, 207, 133-143.

http://dx.doi.org/10.1016/j.foreco.2004.10.023

Karjalainen, T., Pussinen, A., Liski, J., Nabuurs, G. J., Eggers, T., Lapvetelainen, T., \& Kaipainen, T. (2003). Scenario Analysis of the Impacts of Forest Management and Climate Change on the European Forest Sector Carbon Budget. Forest Policy and Economics, 5, 141-155. http://dx.doi.org/10.1016/S1389-9341(03)00021-2

Khadka, C., \& Vacik, H. (2012). Use of Multi-Criteria Analysis (MCA) for Supporting Community Forest Management. iForest - Biogeosciences and Forestry, 5, 60-71. http://dx.doi.org/10.3832/ifor0608-009

Khadka, C., Hujalab, T., Wolfslehnera, B., \& Vacik, H. (2013). Problem Structuring in Participatory Forest Planning. Forest Policy and Economics, 26, 1-11. http://dx.doi.org/10.1016/j.forpol.2012.09.008

Kimmins, J. P., Blanco, J. A., Seely, B., Welham, C., \& Scoullar, K. (2008). Complexity in Modelling Forest Ecosystems: How Much Is Enough? Forest Ecology and Management, 256, 1646-1658. http://dx.doi.org/10.1016/j.foreco.2008.03.011

Kok, K., Patel, M., Rothman, D. S., \& Quaranta, G. (2006). Multi-Scale Narratives from an IA Perspective: Part II. Participatory Local Scenario Development. Futures, 38, 285-311. http://dx.doi.org/10.1016/j.futures.2005.07.006

Kowalski, K., Stagl, S., Madlener, R., \& Omann, I. (2009). Sustainable Energy Futures: Methodological Challenges in Combining Scenarios and Participatory Multi-Criteria Analysis. European Journal of Operational Research, 197, $1063-1074$. http://dx.doi.org/10.1016/j.ejor.2007.12.049 
Krcmar, E., \& van Kooten, G. C. (2008). Economic Development Prospects of Forest-Dependent Communities: Analyzing Trade-Offs Using a Compromise-Fuzzy Programming Framework. American Journal of Agricultural Economics, 90, 1103-1117. http://dx.doi.org/10.1111/j.1467-8276.2008.01149.x

Krcmar, E., van Kooten, G. C., \& Vertinsky, I. (2005). Managing Forests for Multiple Tradeoffs: Compromising on Timber, Carbon Uptake and Biodiversity Objectives. Ecological Modelling, 185, 451-468. http://dx.doi.org/10.1016/j.ecolmodel.2004.12.014

Kumar, A., Flynn, P. C., \& Sokhansanj, S. (2005). Feedstock Availability and Power Costs Associated with Using B.C.'s Beetle-Infested Pine. Victoria: BIOCAP Canada Foundation (Kingston) and the Province of British Columbia.

Leslie, R. N. (2009). The Future of Forests in Asia and the Pacific: Outlook for 2020. FAO, Bangkok (Thailand). Regional Office for Asia and the Pacific; Asia-Pacific Forestry Commission, Bogor (Indonesia).

http://www4.fao.org/cgi-bin/faobib.exe?rec_id=584521\&database=faobib\&search_type=link\&table=mona\&back_path=/f aobib/mona\&lang=eng\&format_name=EFMON

MacKendrick, N., \& Parkins, J. (2005). Socio-Economic Dimensions of Community Vulnerability to Mountain Pine Beetle: Final Report to the Foothills Models Forest. Edmonton: Natural Resources Canada, Canadian Forest Service.

Mendoza, G. A., \& Martins, H. (2006). Multi-Criteria Decision Analysis in Natural Resource Management: A Critical Review of Methods and New Modelling Paradigms. Forest Ecology and Management, 230, 1-22. http://dx.doi.org/10.1016/j.foreco.2006.03.023

Mendoza, G. A., \& Prabhu, R. (2005). Combining Participatory Modeling and Multi-Criteria Analysis for Community-Based Forest Management. Forest Ecology and Management, 207, 145-156. http://dx.doi.org/10.1016/j.foreco.2004.10.024

Montibeller, G., \& Franco, L. A. (2010). Raising the Bar: Strategic Multi-Criteria Decision Analysis. Journal of the Operational Research Society, 62, 855-867. http://dx.doi.org/10.1057/jors.2009.178

Montibeller, G., Gummer, H., \& Tumidei, D. (2006). Combining Scenario Planning and Multi-Criteria Decision Analysis in Practice. Journal of Multi-Criteria Decision Analysis, 14, 5-20.

Ndubisi, F. (2002). Ecological Planning: A Historical and Comparative Synthesis. Baltimore, MD: The Johns Hopkins University Press.

Pahl-Wostl, C. (2002). Participative and Stakeholder-Based Policy Design, Evaluation and Modelling Processes. Integrated Assessment, 3, 3-14. http://dx.doi.org/10.1076/iaij.3.1.3.7409

Pasalodos-Tato, M., Mäkinen, A., Garcia-Gonzalo, J., Borges, J. G., Lämås, T., \& Eriksson, L. O. (2013). Review. Assessing Uncertainty and Risk in Forest Planning and Decision Support Systems: Review of Classical Methods and Introduction of New Approaches. Forest Systems, 22, 282. http://dx.doi.org/10.5424/fs/2013222-03063

Pukkala, T. (Ed.). (2002). Multi-Objective Forest Planning. Managing Forest Ecosystems, Vol. 6. Dordrecht: Kluwer Academic Publishers.

Quesnel Community and Economic Development Corporation (QCEDC) (2008). A Prosperous and Sustainable Way Forward for Quesnel. Quesnel: QCEDC.

Rehfeldt, G. E., \& Jaquish, B. C. (2010). Ecological Impacts and Management Strategies for Western Larch in the Face of Climate-Change. Mitigation and Adaptation Strategies for Global Change, 15, 283-306. http://dx.doi.org/10.1007/s11027-010-9217-2

Robinson, J., \& Tansey, J. (2006). Co-Production, Emergent Properties and Strong Interactive Social Research: The Georgia Basin Futures Project. Science and Public Policy, 33, 151-160.

Romero, C., Amador, F., \& Barco, A. (1987). Multiple Objectives in Agricultural Planning: A Compromise Programming Application. American Journal of Agricultural Economics, 69, 78-86. http://dx.doi.org/10.2307/1241308

Sarewitz, D., \& Pielke, R. A. (2007). The Neglected Heart of Science Policy: Reconciling Supply of and Demand for Science. Environmental Science \& Policy, 10, 5-16. http://dx.doi.org/10.1016/j.envsci.2006.10.001

Schroeder, M. J., \& Lambert, J. H. (2011). Scenario-Based Multiple Criteria Analysis for Infrastructure Policy Impacts and planning. Journal of Risk Research, 14, 191-214. http://dx.doi.org/10.1080/13669877.2010.515314

Stewart, T. J. (2005). Dealing with Uncertainties in MCDA. In J. Figueira, S. Greco, \& M. Ehrgott (Eds.), Multiple Criteria Decision Analysis: State of the Art Surveys (pp. 445-470). Berlin: Springer.

Stewart, T., French, S., \& Rios, J. (2013). Integrating Multicriteria Decision Analysis and Scenario Planning-Review and Extension. Omega-International Journal of Management Science, 41, 679-688.

http://dx.doi.org/10.1016/j.omega.2012.09.003

Stirling, A. (2006). Analysis, Participation and Power: Justification and Closure in Participatory Multi-Criteria Analysis. Land Use Policy, 23, 95-107. http://dx.doi.org/10.1016/j.landusepol.2004.08.010

Swart, R. J., Raskin, P., \& Robinson, J. (2004). The Problem of the Future: Sustainability Science and Scenario Analysis. Global Environmental Change, 14, 137-146. http://dx.doi.org/10.1016/j.gloenvcha.2003.10.002 
Thomson, K. J., \& Psaltopoulos, D. (2005). Economy-Wide Effects of Forestry Development Scenarios in Rural Scotland. Forest Policy and Economics, 7, 515-525. http://dx.doi.org/10.1016/j.forpol.2003.07.005

Volkery, A., Ribeiro, T., Henrichs, T., \& Hoogeveen, Y. (2008). Your Vision or My Model? Lessons from Participatory Land Use Scenario Development on a European Scale. Systemic Practice and Action Research, 21, 459-477.

http://dx.doi.org/10.1007/s11213-008-9104-x

Wollenberg, E., Edmunds, D., \& Buck, L. (2000). Using Scenarios to Make Decisions about the Future: Anticipatory Learning for the Adaptive Co-Management of Community Forests. Landscape and Urban Planning, 47, 65-77. http://dx.doi.org/10.1016/S0169-2046(99)00071-7

\section{Appendix}

About 75 per cent of the productive forest in the Quesnel TSA is classified as timber-harvesting land base. The renewal strategies have already been assigned to recently harvested or naturally disturbed stands. The 621,953hectare model land base consists of stands older than 40 years. The land base is divided into strata according to tree species, site index and age classes, biogeoclimatic zones and severity of beetle attack. The forest resources include four predominant species: interior Douglas fir, spruce (except black spruce), lodgepole pine and deciduous species (mainly aspen) growing on the three productivity site index classes of poor, medium and good.

The beetle attack data for the Quesnel TSA are available as a percentage of the area of susceptible stands. Each stratum is assigned to existing and future yield table projections generated by TIPSY 4.1 (B.C. MoF, 2007). Stands are assumed to be harvested when their volume reaches at least $140 \mathrm{~m}^{3} / \mathrm{ha}$ (FESL, 2008).

The revenue $r_{m t}(\$)$ from timber sales depends on the quantity and quality of the volume harvested; the merchantable volume is categorized into different grades, which draw different prices. The grade is based on the length and diameter of the log pieces. The revenues are calculated as $r_{m t}(\$)=\mathrm{a}_{\mathrm{s}, \mathrm{g}}\left(\$ / \mathrm{m}^{3}\right) \times v_{m p t}\left(\mathrm{~m}^{3}\right)$ where $\mathrm{a}_{\mathrm{s}, \mathrm{g}}\left(\$ / \mathrm{m}^{3}\right)$ is the price per cubic metre of species $s$ and grade $g$ wood. The harvest costs consist of silviculture and tree-to-truck costs. The harvest costs are calculated as $h c_{m p t}(\$)=b_{\mathrm{s}, \mathrm{p}}\left(\$ / \mathrm{m}^{3}\right) \times v_{m p t}\left(\mathrm{~m}^{3}\right)$ where $b_{\mathrm{s}, \mathrm{p}}\left(\$ / \mathrm{m}^{3}\right)$ is the cost per cubic metre of species $s$ managed by practice $p$. Selling prices and harvest costs used in the project are presented in Table A1.

Table A1. Selling prices and harvest costs $\left(\$ / \mathrm{m}^{3}\right)$.

\begin{tabular}{cccccc}
\hline & \multicolumn{3}{c}{ Grade } & \multicolumn{2}{c}{ Harvest costs } \\
\hline Species & 1 & 2 & 4 & Silviculture $(\$ / \mathrm{ha})$ & Tree-to-truck $\left(\$ / \mathrm{m}^{3}\right)$ \\
\hline Fir & 57.77 & 57.77 & 27.61 & 1038 & 18 \\
Spruce & 47.23 & 47.23 & 31.93 & 1061 & 18 \\
Pine & 47.23 & 47.23 & 39.58 & 823 & 943 \\
Deciduous & 26.00 & 26.00 & 26.00 & 1148 & 16 \\
Western Larch & 57.77 & 57.77 & 27.61 & 16 \\
\hline
\end{tabular}

Sources: FESL (2008). 
Scientific Research Publishing (SCIRP) is one of the largest Open Access journal publishers. It is currently publishing more than 200 open access, online, peer-reviewed journals covering a wide range of academic disciplines. SCIRP serves the worldwide academic communities and contributes to the progress and application of science with its publication.

Other selected journals from SCIRP are listed as below. Submit your manuscript to us via either submit@scirp.org or Online Submission Portal.
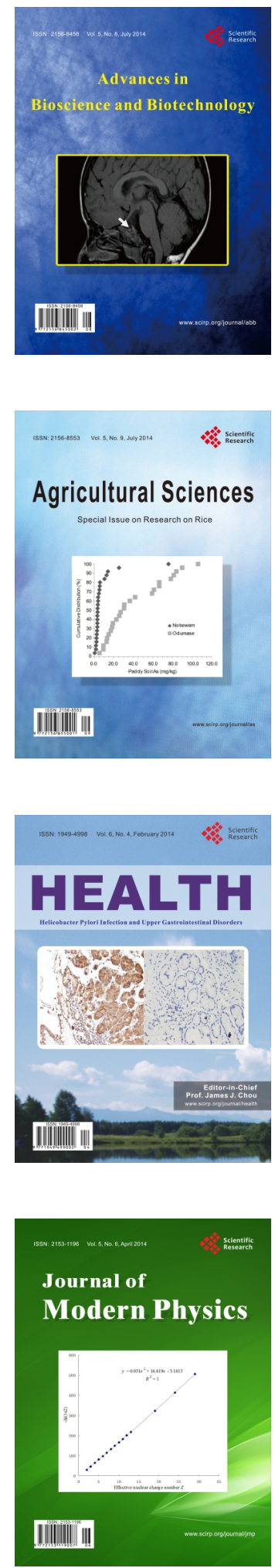
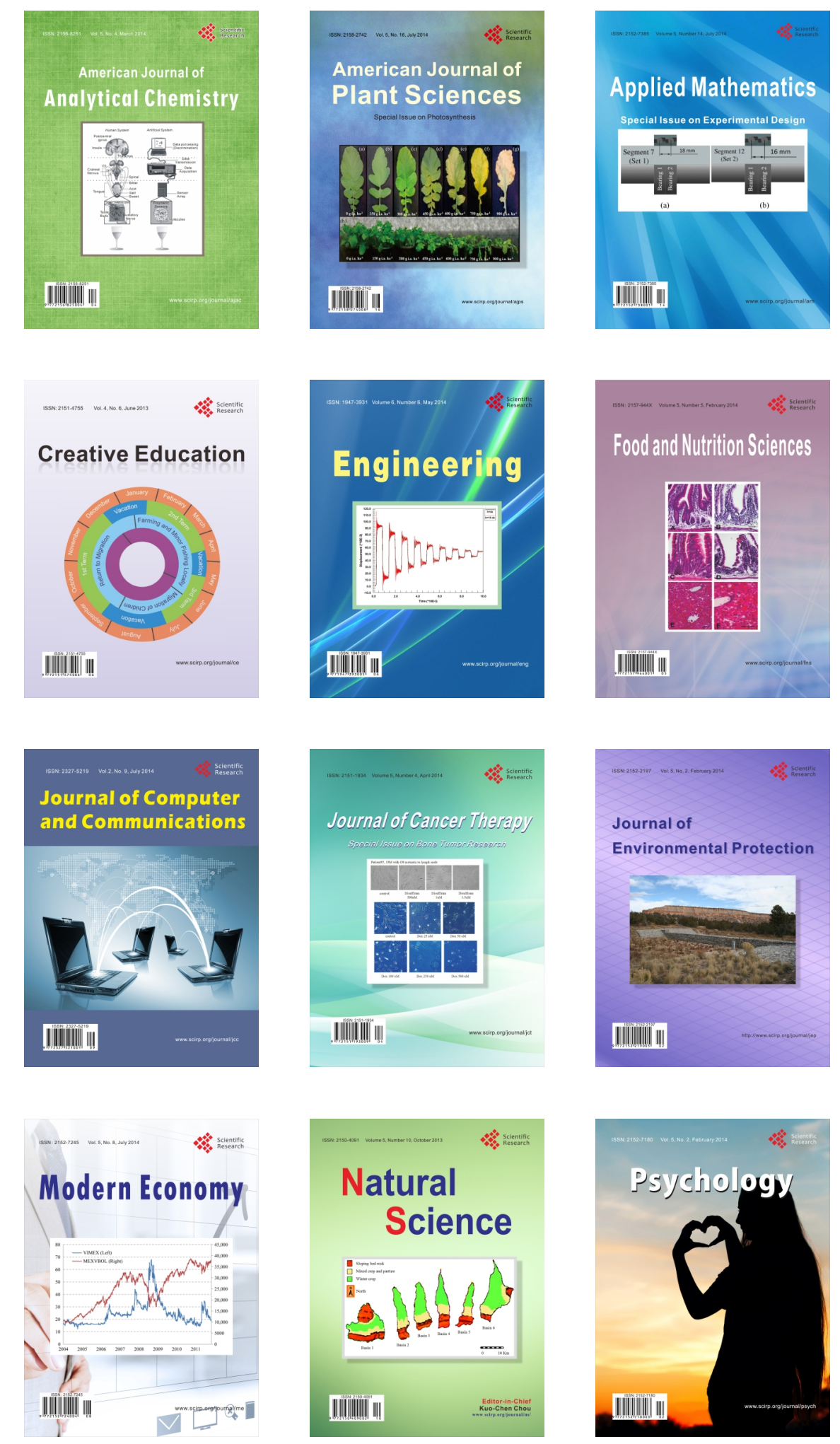